\title{
Does Biosimilar Bevacizumab Offer Affordable Treatment Options for Cancer Patients in the USA? A Budget Impact Analysis from US Commercial and Medicare Payer Perspectives
}

\author{
Jingyan Yang ${ }^{1,2} \cdot{\text { Rongzhe } \text { Liu }^{3} \cdot \text { Varun Ektare }^{3} \cdot \text { Jennifer Stephens }}^{3} \cdot$ Ahmed Shelbaya $^{1,4}$
}

Accepted: 3 January 2021 / Published online: 28 January 2021

(c) The Author(s) 2021

\begin{abstract}
Background Bevacizumab remains the most widely used and most thoroughly characterized angiogenesis inhibitor for a range of advanced cancers. Bevacizumab-bvzr (Zirabev $\left.{ }^{\circledR}\right)$, a biosimilar of bevacizumab, was recently approved by the US Food and Drug Administration (FDA), which provides a less costly option. This study aimed to evaluate the financial impact of introducing bevacizumab-bvzr from US commercial and Medicare payer perspectives.

Methods A Microsoft Excel-based budget impact model was developed over a 5-year time horizon. Target population was patients to be treated with bevacizumab for FDA-approved indications. Drug costs (2020 US\$) were based on average sales price and wholesale acquisition cost, accounting for payer-specific reimbursement models and provider settings. Drug dosing and duration were based on prescribing information and pivotal trial publications.

Results In a hypothetical 10-million-member health plan, 503 and 723 patients were estimated to be treated with bevacizumab in year 1 and year 5, respectively. Assuming an annual market shift of 1.7\%, 3.6\%, 6.7\%, 9.4\%, and 11.9\% to bevacizumabbvzr, an annual cost saving of $\$ 313,363$ ( $\$ 0.003$ per member per month [PMPM]) was estimated for a commercial payer and $\$ 92,880$ (\$0.001 PMPM) for Medicare in year 1. Cumulative 5-year cost savings were $\$ 7,030,924$ (\$0.012 PMPM) for a commercial payer and $\$ 4,059,257$ ( $\$ 0.007$ PMPM) for Medicare. More than half of the cost savings was attributed to patients with metastatic colorectal cancer.

Conclusions The introduction of biosimilar bevacizumab-bvzr was estimated to provide substantial cost savings for US payers, which would allow additional patients access to bevacizumab treatment.
\end{abstract}

\section{Key Points for Decision Makers}

The introduction of biosimilar bevacizumab-bvzr provides substantial cost savings for US payers due to significant efficiency savings in direct acquisition.

Biosimilars may allow the delivery of high-value care through expanded use of biologic treatment during episodes of cancer care.

Jingyan Yang

jingyan.yang@pfizer.com

1 Patient Health and Impact (PHI), Pfizer Inc., 235 East 42nd Street, New York, NY 10017, USA

2 Institute for Social and Economic Research and Policy (ISERP), Columbia University, New York, NY, USA

3 Pharmerit, an OPEN Health Company, Bethesda, MD, USA

4 Mailman School of Public Health, Columbia University, New York, NY, USA

\section{Introduction}

Bevacizumab (Avastin ${ }^{\circledR}$ ) is a recombinant humanized monoclonal IgG1 antibody and was the first anti-angiogenic oncology approved in the USA [1]. Bevacizumab binds to vascular endothelial growth factors (VEGFs), which prevents the interaction of VEGFs with endothelial cell receptors and blocks cell proliferation and the formation of new blood vessels. Bevacizumab was initially approved for the treatment of metastatic colorectal cancer (mCRC) in the USA in 2004 [2]. It is now indicated for a range of solid tumor indications including: first-line unresectable, locally advanced, recurrent, or metastatic non-squamous nonsmall-cell lung cancer (NSCLC) [3]; metastatic renal cell carcinoma (mRCC) [4]; recurrent glioblastoma (rGBM) [5]; persistent, recurrent, or metastatic cervical cancer (mCC) [6]; unresectable hepatocellular carcinoma [7]; first- and second-line metastatic colorectal cancer (mCRC) [8,9]; and stage III or IV epithelial ovarian, fallopian tube, or primary 
peritoneal cancer following initial surgical resection [10]. Despite more anti-angiogenic therapies becoming available in recent years $[11,12]$, bevacizumab remains the most widely used angiogenesis inhibitor [13]. When used in addition to standard-of-care chemotherapy, bevacizumab provides an effective therapeutic option in cancer patients [13].

However, biologic therapies are among the most expensive drugs, accounting for $40 \%$ of total US spending on prescription drugs despite only $2 \%$ of patients using biologics [14]. High development and treatment costs associated with biologics may limit patient access to these therapies. According to a physician survey conducted in the USA, Europe, and emerging markets, high out-of-pocket costs of bevacizumab are a barrier to prescribing bevacizumab and are a common reason physicians reduce the number of planned treatment cycles [15]. Previous studies that performed economic evaluations of bevacizumab have demonstrated a lack of cost-effectiveness in patients with mCRC in the USA, UK, Canada, Australia, and Israel [16-18], rGBM in Canada [19], $\mathrm{mCC}$ in the USA [20], and ovarian cancer in Canada and Belgium [21, 22], although the cost-effectiveness of bevacizumab in NSCLC was not conclusive according to a systematic review including ten countries [23].

Given the high cost of bevacizumab, which was among the top ten drug expenditures in the USA in 2018 for the Medicare Part B program [24], the introduction of biosimilars provides an opportunity for increased patient access and decreased healthcare expenditures across a number of oncologic indications. According to a RAND study, the introduction of biosimilars in the USA will result in substantial savings in the biologics market, potentially reducing direct spending on biologic drugs by $\$ 54$ billion from 2017 to 2026 [25].

A biosimilar is defined as a biologic product that is "highly similar to the reference product notwithstanding minor differences in clinically inactive components," and one in which "there are no clinically meaningful differences between the biologic product and the reference product in terms of the safety, purity, and potency of the product" [14]. Given the definition, biosimilars are approved through an abbreviated regulatory process, which focuses more on pharmaceutical and pharmacologic properties of the protein than safety and efficacy data [26].

Biosimilar bevacizumab-bvzr (Zirabev ${ }^{\circledR}$, Pfizer, Inc., NY, USA) has been approved by the US Food and Drug Administration (FDA) in June 2019 for all eligible indications (i.e., not covered by regulatory exclusivity) authorized for the reference product [27]. Bevacizumab-bvzr is the secondto-market biosimilar for bevacizumab in the USA, following bevacizumab-awwb (Mvasi ${ }^{\circledR}$, Amgen, Inc., CA, USA), which was approved by the US FDA in 2017 [28]. The biosimilarity of bevacizumab-bvzr to the reference product was supported by a double-blind, parallel-group study (ClinicalTrials.gov, NCT02364999) that compared the efficacy and safety of biosimilar bevacizumab with that of the reference product, each with paclitaxel and carboplatin, in the first-line treatment of advanced non-squamous NSCLC [29]. There were no clinically meaningful differences in safety, pharmacokinetics, or immunogenicity across treatment groups [29].

In order to encourage lower-cost biosimilars in the USA, Medicare has introduced differential reimbursement for biosimilars. Specifically, provider-administered biologics are reimbursed at the product's average sale price (ASP) plus $6 \%$ of the ASP. In contrast, a biosimilar is reimbursed at the biosimilar's own ASP plus $6 \%$ of the originator biologic's ASP [30]. Medicare biosimilar reimbursement may shift the incentive to lower-cost biosimilars among healthcare providers. In order to understand the potential savings if bevacizumab-bvzr is widely adopted in the USA, a budget impact model was developed to estimate the financial impact of introducing bevacizumab-bvzr to the formulary for the treatment of all FDA-approved indications from US commercial and Medicare payer perspectives.

\section{Methodology}

\subsection{Model Overview}

A budget impact model (BIM) was developed in Microsoft Excel (Microsoft Corp., Redmond, WA, USA) to estimate the financial impact of introducing bevacizumab-bvzr to a payer's formulary in the USA. A hypothetical 10-millionmember health plan was assumed. The target population was defined as patients treated with bevacizumab for all FDA-approved indications, including first-line unresectable, locally advanced, recurrent or metastatic non-squamous NSCLC, mRCC, rGBM, persistent, recurrent, or metastatic $\mathrm{CC}$, and first-line and second-line mCRC.

The analysis was conducted from US commercial payer and Medicare perspectives separately. Patient cost exposure such as co-payment or co-insurance was not considered. The budget impact of bevacizumab-bvzr was estimated by comparing the total costs between two scenarios annually over a 5-year time horizon (Fig. 1). The first scenario reflected a formulary in which all the patients treated with bevacizumab are on either the reference product (Avastin ${ }^{\circledR}$, Genentech, CA, USA) or bevacizumab-awwb (Mvasi ${ }^{\mathrm{TM}}$, Amgen, CA, USA), a bevacizumab biosimilar currently available in the US market, whereas the second scenario reflected a hypothetical new formulary where bevacizumab-bvzr was introduced. In the second scenario, a proportional market shift was assumed from the existing products to bevacizumabbvzr in each year following biosimilar launch. The total drug costs for both scenarios were estimated as the sum of product of the number of eligible patients on each treatment and annual per-patient cost of specific medication. The budget 
impact was estimated as the difference in total costs between the scenarios with and without bevacizumab-bvzr. Given the aim of the BIM was to compare annual cash flows, no discounting was applied [31]. Reporting of the study was guided by the consolidated health economic evaluation reporting standards (CHEERS) statement [32].

Costs associated with drug administration, adverse events (AEs), efficacy, and other healthcare resource utilization were assumed to be the same between bevacizumab biosimilars and reference product, and therefore non-drug costs were not included in the analysis. This assumption is consistent with the definition of biosimilar biologics and is supported by clinical trial data [29].

\subsection{Target Population}

The estimation of patients initiating treatment with bevacizumab for all FDA-approved indications was conducted in two steps. First, the number of eligible patients in each year was estimated based on hypothetical health plan size, growth rate of plan population, and US-based epidemiology (Table 1). The incidence of each cancer indication and other disease burden data were obtained from the Surveillance, Epidemiology, and End Results (SEER) Cancer Statistics Review [33] and published literatures (referenced in Table 1), which were assumed to be the same for commercial payers and Medicare. The present analysis only included an incident population that was newly diagnosed in each model year. Treatment utilization rates of bevacizumab were applied to the number of eligible patients by indication, assuming that the utilization of bevacizumab would remain constant over time and that only the patients treated with bevacizumab reference product would switch to bevacizumab biosimilar. It was also assumed that all the patients initiating treatment with bevacizumab in a specific year started the treatment in the beginning of the year.

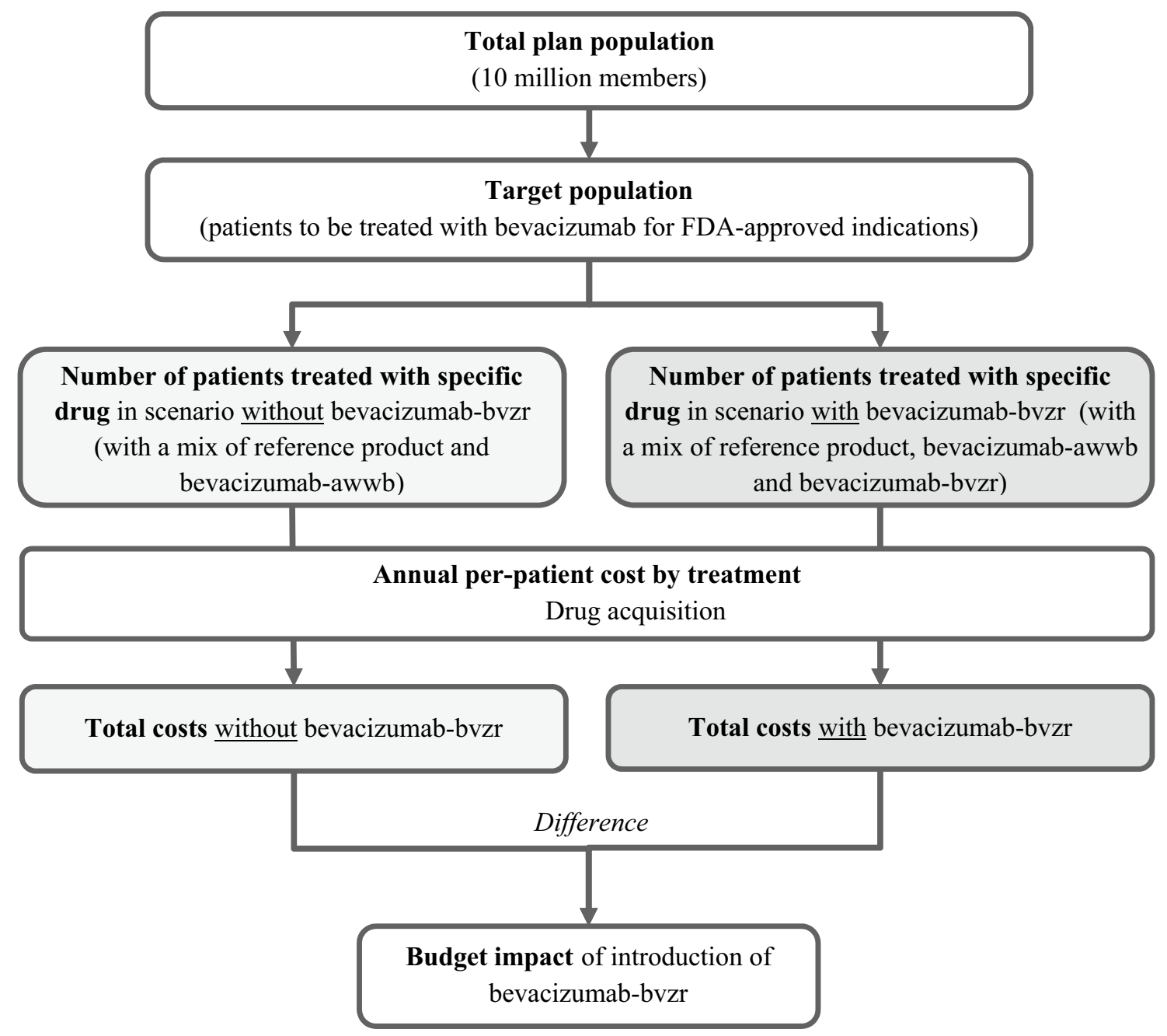

Fig. 1 Simplified model framework 
Table 1 Epidemiology, treatment utilization of bevacizumab biologics, and number of patients initiating treatment with bevacizumab

\begin{tabular}{|c|c|c|c|c|c|c|}
\hline \multirow[t]{2}{*}{ Parameter } & \multirow[t]{2}{*}{ Value } & \multicolumn{5}{|c|}{ Estimated population initiating treatment with bevaciuzumab } \\
\hline & & Year 1 & Year 2 & Year 3 & Year 4 & Year 5 \\
\hline Plan population in year 1 & $10,000,000$ & & & & & \\
\hline Annual population growth rate [64] & $0.6 \%$ & $10,000,000$ & $10,062,572$ & $10,125,535$ & $10,188,893$ & $10,252,647$ \\
\hline \multicolumn{7}{|c|}{ First-line unresectable, locally advanced, recurrent or metastatic non-squamous non-small-cell lung cancer } \\
\hline Incidence, non-small-cell lung cancer (per 100,000) [33] & 38.7 & 3871 & 3895 & 3920 & 3944 & 3969 \\
\hline Proportion with non-squamous disease [65] & $73.7 \%$ & 2854 & 2872 & 2890 & 2908 & 2926 \\
\hline Proportion with advanced disease [66] & $58.8 \%$ & 1679 & 1690 & 1700 & 1711 & 1721 \\
\hline Proportion receiving first-line treatment [67] & $46.0 \%$ & 772 & 777 & 782 & 787 & 792 \\
\hline Proportion treated with bevacizumab [68] & $23.6 \%$ & $182^{\mathrm{a}}$ & 183 & 185 & 186 & 187 \\
\hline \multicolumn{7}{|l|}{ Metastatic renal cell carcinoma } \\
\hline Incidence, kidney cancer (per 100,000) [33] & 15.7 & 1570 & 1580 & 1590 & 1600 & 1610 \\
\hline Proportion with renal cell carcinoma [65] & $90.8 \%$ & 1426 & 1435 & 1444 & 1453 & 1462 \\
\hline Proportion with metastatic disease [65] & $13.3 \%$ & 189 & 191 & 192 & 193 & 194 \\
\hline Proportion receiving first-line treatment [69] & $85.1 \%$ & 161 & 162 & 163 & 164 & 165 \\
\hline $\begin{array}{l}\text { Proportion receiving second-line treatment among patients } \\
\text { receiving first-line treatment [69] }\end{array}$ & $62.0 \%$ & 100 & 101 & 101 & 102 & 102 \\
\hline $\begin{array}{l}\text { Proportion receiving third-line treatment among patients receiv- } \\
\text { ing second-line treatment [70] }\end{array}$ & $47.0 \%$ & 47 & 47 & 48 & 48 & 48 \\
\hline $\begin{array}{l}\text { Proportion receiving fourth-line treatment among patients } \\
\text { receiving third-line treatment [70] }\end{array}$ & $32.8 \%$ & 15 & 15 & 16 & 16 & 16 \\
\hline Proportion treated with bevacizumab ${ }^{\mathrm{b}}$ & $1.0 \%$ & $3^{\mathrm{c}}$ & 3 & 3 & 3 & 3 \\
\hline \multicolumn{7}{|l|}{ Recurrent glioblastoma } \\
\hline Incidence, brain cancer (per 100,000) [33] & 6.5 & 650 & 654 & 658 & 662 & 666 \\
\hline Proportion with glioblastoma [65] & $51.5 \%$ & 335 & 337 & 339 & 341 & 343 \\
\hline Proportion receiving first-line treatment [71] & $49.9 \%$ & 167 & 168 & 169 & 170 & 171 \\
\hline $\begin{array}{l}\text { Proportion receiving second-line treatment among patients } \\
\text { receiving first-line treatment [71] }\end{array}$ & $32.6 \%$ & 54 & 55 & 55 & 55 & 56 \\
\hline Proportion treated with bevacizumab [72] & $36.0 \%$ & $80^{\mathrm{d}}$ & 80 & 81 & 81 & 82 \\
\hline \multicolumn{7}{|l|}{ Persistent, recurrent, or metastatic cervical cancer } \\
\hline Incidence, cervical cancer (per 100,000) [33] & 6.7 & 668 & 672 & 676 & 681 & 685 \\
\hline Proportion with metastatic disease [33] & $15.6 \%$ & 104 & 105 & 106 & 106 & 107 \\
\hline Proportion with recurrent disease [73] & $22.5 \%$ & 150 & 151 & 152 & 153 & 154 \\
\hline Proportion receiving first-line treatment [74] & $52.3 \%$ & 133 & 134 & 135 & 136 & 137 \\
\hline $\begin{array}{l}\text { Proportion receiving second-line treatment among patients } \\
\text { receiving first-line treatment [74] }\end{array}$ & $32.4 \%$ & 43 & 44 & 44 & 44 & 44 \\
\hline Proportion treated with bevacizumab ${ }^{\mathrm{e}}$ & $1.0 \%$ & $2^{\mathrm{f}}$ & 2 & 2 & 2 & 2 \\
\hline \multicolumn{7}{|l|}{ First-line and second-line metastatic colorectal cancer } \\
\hline Incidence, colorectal cancer (per 100,000) [33] & 37.0 & 3700 & 3723 & 3746 & 3770 & 3793 \\
\hline Proportion with metastatic disease [75] & $22.3 \%$ & 825 & 830 & 835 & 841 & 846 \\
\hline Proportion receiving first-line treatment [76] & $69.7 \%$ & 575 & 579 & 583 & 586 & 590 \\
\hline $\begin{array}{l}\text { Proportion receiving second-line treatment among patients } \\
\text { receiving first-line treatment [76] }\end{array}$ & $60.9 \%$ & 350 & 352 & 354 & 357 & 359 \\
\hline Proportion treated with bevacizumab [77] & $48.3 \%$ & $447^{\mathrm{g}}$ & 450 & 453 & 456 & 458 \\
\hline
\end{tabular}

${ }^{\text {a}}$ Estimated as: $10,000,000 * 38.7 / 100,000 * 73.7 \% * 58.8 \% * 46.0 \% * 23.6 \%$

bestimated as: As bevacizumab was not reported in any published real-world study for mRCC in the USA or UK [69, 70, 78, 79], indicating that bevacizumab was rarely used for mRCC, an uptake of $1 \%$ was assumed

${ }^{c}$ Estimated as: $10,000,000 * 15.7 / 100,000 * 90.8 \% * 13.3 \% * 85.1 \% *(1+62.0 \% *(1+47.0 \% *(1+32.8 \%))) * 1 \%$

${ }^{\mathrm{d}}$ Estimated as: $10,000,000 * 6.5 / 100,000 * 51.5 \% * 49.9 \% *(1+32.6 \%) * 36.0 \%$

${ }^{\mathrm{e}}$ As there was rarely any published real-world treatment pattern study in cervical cancer 15 , an uptake of $1 \%$ was assumed

f Estimated as: $10,000,000 * 6.7 / 100,000 *(15.6 \%+22.5 \%) * 52.3 \% *(1+32.4 \%) * 1 \%$

g Estimated as: $10,000,000 * 37.0 / 100,000 * 22.3 \% * 69.7 \% *(1+60.9 \%) * 48.3 \%$ 


\subsection{Treatment Duration}

To account for treatment discontinuation due to disease progression, unacceptable toxicity, or death, the cumulative proportion of patients discontinuing treatment over time since treatment initiation was applied to the number of patients initiating treatment with bevacizumab in each year.

The cumulative proportion of patients discontinuing treatment was estimated based on the median treatment duration obtained from pivotal trial publications for bevacizumab reference product (Table 2), assuming that treatment discontinuation followed an exponential distribution (e.g., at a constant rate of treatment discontinuation) and that patients would discontinue treatment at mid-year (i.e., $0.5,1.5,2.5,3.5$, and 4.5 years since treatment initiation). The proportion of patients remaining on treatment was estimated as one minus the cumulative proportion of patients discontinuing treatment and then applied to both bevacizumab reference product and bevacizumab-bvzr, assuming that there was no difference in treatment discontinuation. The total number of eligible patients treated with bevacizumab in each year was estimated as the sum of the number of patients initiating treatment in the current year and the number of patients initiating treatment in previous year(s) but still remaining on treatment this year.

\subsection{Treatment Distribution}

Comparators to bevacizumab-bvzr in the present analysis were its reference biologic and biosimilar bevacizumabawwb. In the scenario without bevacizumab-bvzr, it was assumed that all the patients on bevacizumab would be treated with either reference product or bevacizumabawwb, using the projected treatment distributions from historical market research data [34]. In the scenario with bevacizumab-bvzr, it was assumed that the uptake of bevacizumab-bvzr was proportionally taken from reference product and bevacizumab-awwb, with respect to the projected treatment distributions of these two drugs over years 1-5. Projected treatment distributions were assumed to be uniform across indications (Table 3).

\subsection{Treatment Costs}

The estimation of annual per-patient drug costs accounted for payer-specific reimbursement models and site of care (Table 4). Drug cost from a commercial payer perspective was estimated as a weighted average of costs of drugs administered in physician office $(48 \%)$ and hospital outpatient setting (52\%) [34]. Costs in physician offices was estimated using average sales price (ASP) with $10 \%$ cost recovery [35-38]. Costs in a hospital outpatient setting were typically a percentage of billed changes, as a proxy of which, wholesale acquisition cost (WAC) with $75 \%$ cost recovery was applied [35-37, 39]. The calculation of drug costs from a commercial payer perspective was the same between reference product and biosimilars.

Table 3 Projected treatment distribution over 5 years

\begin{tabular}{lrrrrr}
\hline $\begin{array}{l}\text { Market scenario and } \\
\text { treatment option }\end{array}$ & \multicolumn{5}{l}{ Treatment distribution (\%) } \\
\cline { 2 - 6 } & Year 1 & Year 2 & Year 3 & Year 4 & Year 5 \\
\hline Without bevacizumab-bvzr & & & & \\
Bevacizumab & 79.0 & 70.1 & 72.7 & 66.5 & 61.2 \\
Bevacizumab-awwb & 21.0 & 29.9 & 27.3 & 33.5 & 38.8 \\
Bevacizumab-bvzr & 0.0 & 0.0 & 0.0 & 0.0 & 0.0 \\
With bevacizumab-bvzr & & & & & \\
Bevacizumab & 77.6 & 67.6 & 67.8 & 60.2 & 53.9 \\
Bevacizumab-awwb & 20.7 & 28.8 & 25.5 & 30.4 & 34.2 \\
Bevacizumab-bvzr & 1.7 & 3.6 & 6.7 & 9.4 & 11.9 \\
\hline
\end{tabular}

Table 2 Median treatment duration and proportion of patients remaining on treatment

\begin{tabular}{|c|c|c|c|c|c|c|c|}
\hline \multirow[t]{2}{*}{ Indication } & \multirow{2}{*}{$\begin{array}{l}\text { Median treatment } \\
\text { duration (month) }\end{array}$} & \multicolumn{6}{|c|}{ Patients remaining on treatment } \\
\hline & & Baseline (\%) & $\begin{array}{l}\text { After } 0.5 \\
\text { year }(\%)\end{array}$ & $\begin{array}{l}\text { After } 1.5 \\
\text { years }(\%)\end{array}$ & $\begin{array}{l}\text { After } 2.5 \\
\text { years }(\%)\end{array}$ & $\begin{array}{l}\text { After } 3.5 \\
\text { years }(\%)\end{array}$ & $\begin{array}{l}\text { After } \\
4.5 \text { years } \\
(\%)\end{array}$ \\
\hline Non-small-cell-lung cancer [80] & 4.9 & 100 & 43 & 8 & 1 & 0 & 0 \\
\hline Metastatic renal cell carcinoma [4] & 9.7 & 100 & 65 & 27 & 12 & 5 & 2 \\
\hline Recurrent glioblastoma [5] & $4.1^{\mathrm{a}}$ & 100 & 37 & 5 & 1 & 0 & 0 \\
\hline Cervical cancer $[81]$ & $4.8^{\mathrm{b}}$ & 100 & 42 & 8 & 1 & 0 & 0 \\
\hline Metastatic colorectal cancer $[8,9,82]$ & $4.6^{\mathrm{c}}$ & 100 & 40 & 7 & 1 & 0 & 0 \\
\hline
\end{tabular}

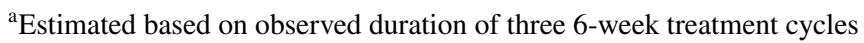

${ }^{\mathrm{b}}$ Estimated based on observed duration of seven 21-day treatment cycles

${ }^{\mathrm{c}}$ Estimated based on observed duration of ten 14-day treatment cycles and was applied to estimate the proportion of patients remaining on treatment 
Drug cost from a Medicare perspective was estimated as a weighted average of costs in non-340B entities $(63 \%)$ and 340B entities (37\%) [34]. Reimbursement to non-340B entities for reference product was estimated as the ASP of reference product plus $6 \%$ of ASP of reference product, while reimbursement to non-340B entities for bevacizumab biosimilars was estimated as the ASP of bevacizumab biosimilars plus $6 \%$ of ASP of reference product, in line with CMS reimbursement policy for biosimilars [30]. Reimbursement to 340B entities for reference product was estimated as the ASP of reference product minus $22.5 \%$ of ASP of reference product [40]. However, reimbursement to $340 \mathrm{~B}$ entities for bevacizumab biosimilars was estimated as the ASP of bevacizumab biosimilars plus $6 \%$ of ASP of reference product in the first 2 years of the model and estimated as the ASP of bevacizumab biosimilars minus $22.5 \%$ of ASP of bevacizumab biosimilars in years 3-5, assuming a 2-year duration of pass-through phase [41]. The ASPs and WACs of all products were obtained from Centers for Medicare and Medicaid Services [42] and RED BOOK [43], respectively. All costs were in 2020 US dollars.

Drug dosage was based on prescribing information (Table 5) [27, 44]. As bevacizumab reference product and biosimilars are dosed based on patient weights, average patient weights in each indication were estimated based on sex ratio from pivotal trial publications of the reference product and average weights for the general US population [45]. Costs of product wastage were included, given bevacizumab-bvzr is indicated as a single-dose vial [46].

\subsection{Analysis}

For both market scenarios with and without bevacizumabbvzr, the total annual costs to the health plan in year 1 to year 5 were estimated as the sum of product of the number of eligible patients treated with specific medication in each year and the annual per-patient costs of specific medication.

The total budget impact was calculated as the difference in total costs between the scenarios with and without bevacizumab-bvzr for the entire target population in aggregate. In addition, budget impacts per member per year (PMPY), per member per month (PMPM), per patient per month (PPPM), and per patient per year (PPPY) were estimated. The PMPY budget impact was estimated by dividing the total budget impact to the health plan by the number of members in the plan. The PMPM budget impact was estimated by dividing the PMPY budget impact by 12 months. The PPPY budget impact was estimated by dividing the total budget impact to the health plan by the number of patients in the target population in the plan. The PPPM budget impact was estimated by dividing the PPPY budget impact by 12 months. In addition, additional number of patients treatable with bevacizumab-bvzr for a 1-year treatment course was estimated by dividing the total cost savings in specific year by the annual per-patient cost of bevacizumab-bvzr by indication.

Scenario analyses were conducted to assess the impact of key parameters on the results, including comparing market scenarios with and without bevacizumab biosimilars, change in bevacizumab-bvzr ASP, variations in projected uptake of

Table 4 Drug costs

\begin{tabular}{|c|c|c|c|c|c|}
\hline \multirow[t]{2}{*}{ Treatment } & \multicolumn{2}{|c|}{ Cost inputs per $100 \mathrm{mg}$ vial } & \multicolumn{3}{|c|}{ Estimated costs per $100 \mathrm{mg}$ vial by payer } \\
\hline & $\begin{array}{l}\text { Average sales } \\
\text { price [42] }\end{array}$ & $\begin{array}{l}\text { Wholesale acqusi- } \\
\text { tion cost [42] }\end{array}$ & $\begin{array}{l}\text { Medicare } \\
\text { (year 1-2) }\end{array}$ & $\begin{array}{l}\text { Medicare } \\
\text { (year 3-5) }\end{array}$ & $\begin{array}{l}\text { Commer- } \\
\text { cial (year } \\
1-5)\end{array}$ \\
\hline Bevacizumab & $\$ 783.99$ & $\$ 796.94$ & $\$ 748$ & $\$ 748$ & $\$ 1,139$ \\
\hline Bevacizumab-awwb & $\$ 624.22$ & $\$ 677.40$ & $\$ 671$ & $\$ 596$ & $\$ 898$ \\
\hline Bevacizumab-bvzr & $\$ 631.80$ & $\$ 613.40$ & $\$ 679$ & $\$ 603$ & $\$ 909$ \\
\hline
\end{tabular}

${ }^{\text {a } P a y e r-s p e c i f i c ~ r e i m b u r s e m e n t ~ m o d e l s ~ a n d ~ s i t e ~ o f ~ c a r e ~ w e r e ~ a c c o u n t e d ~ f o r ~}$

Table 5 Drug dosage

\begin{tabular}{|c|c|c|c|c|c|c|}
\hline Indication & Male $(\%)$ & $\begin{array}{l}\text { Average } \\
\text { weight }(\mathrm{kg})^{\mathrm{a}}\end{array}$ & $\begin{array}{l}\text { Dosage (mg/ } \\
\mathrm{kg})\end{array}$ & $\begin{array}{l}\text { Dose per } \\
\operatorname{admin}(\mathrm{mg})\end{array}$ & $\begin{array}{l}\text { Admin fre- } \\
\text { quency (days) }\end{array}$ & Admin per year \\
\hline Non-small-cell-lung cancer [80] & 54.4 & 83.1 & 15 & 1247 & 21 & 17.4 \\
\hline Metastatic renal cell carcinoma [4] & 70.5 & 85.1 & 10 & 851 & 14 & 26.1 \\
\hline Recurrent glioblastoma [5] & 60.6 & 83.9 & 10 & 839 & 14 & 26.1 \\
\hline Cervical cancer $[81]$ & 0.0 & 76.4 & 15 & 1146 & 21 & 17.4 \\
\hline Metastatic colorectal cancer $[8,9,82]$ & 60.4 & 83.9 & 7.5 & 629 & 14 & 26.1 \\
\hline
\end{tabular}

${ }^{a}$ Average patient weights in each indication were estimated based on sex ratio from pivotal trial publications of the reference product and average weights ( $88.8 \mathrm{~kg}$ in males, $76.4 \mathrm{~kg}$ in females) for the general US population [45] 
bevacizumab-bvzr and reimbursement markups, and time horizon.

\section{Results}

\subsection{Base-Case Analysis}

In a hypothetical 10-million-member US health plan, the numbers of patients to be treated with bevacizumab were estimated to be 503, 676, 709, 718, and 723 in year 1 through year 5 , respectively (Table 6). The mCRC accounted for $62 \%$ of the total treated population, followed by NSCLC and recurrent glioblastoma, which accounted for $26 \%$ and $11 \%$ of the total treated population, respectively.

For a hypothetical 10-million-member commercial payer, bevacizumab-bvzr was associated with a total annual cost savings of $\$ 313,363$ (\$0.003 PMPM) in year 1, \$771,922 (\$0.006 PMPM) in year 2, \$1,564,205 (\$0.013 PMPM) in year 3, \$2,020,307 (\$0.017 PMPM) in year 4 , and $\$ 2,361,127$ (\$0.019 PMPM) in year 5, resulting in a cumulative cost savings of $\$ 7,030,924$ (\$0.012 PMPM) over 5 years. The total annual costs savings would provide additional access to a 1-year treatment course of bevacizumabbvzr for two patients, four patients, nine patients, 11 patients, and 13 patients in year 1 through year 5 (Table 6).

From a Medicare perspective, bevacizumab-bvzr resulted in a total annual cost savings of $\$ 92,880$ (\$0.001 PMPM) in year $1, \$ 226,412$ (\$0.002 PMPM) in year $2, \$ 984,312$ (\$0.008 PMPM) in year 3, \$1,270,889 (\$0.010 PMPM) in year 4 , and $\$ 1,484,765$ (\$0.012 PMPM) in year 5, leading to a cumulative cost savings of $\$ 4,059,257$ ( $\$ 0.007$ PMPM) over 5 years. The total annual costs savings would allow additional one patient, three patients, eight patients, 11 patients, and 12 patients in year 1 through year 5 to have access to a 1-year treatment course of bevacizumab-bvzr (Table 6).

\subsection{Scenario Analyses}

In the scenario analysis where a market scenario with bevacizumab biosimilars (including both bevacizumab-awwb and bevacizumab-bvzr) was compared to a market scenario with only the reference product, the cost savings were estimated to be $\$ 0.093$ PMPM ( $+675 \%$ relative to base case) for a commercial payer and $\$ 0.050$ PMPM $(+614 \%$ relative to base case) for Medicare averaged across a 5-year time horizon (Table 7).

Assuming that the ASP of bevacizumab-bvzr decreased by $10 \%$, it would result in an average cost saving of $\$ 0.018$ PMPM $(+50 \%$ relative to base case) for a commercial payer and $\$ 0.011$ PMPM ( $+57 \%$ relative to base case) for Medicare. Decreasing bevacizumab-bvzr ASP by $20 \%$ would further increase the average cost saving to \$0.025 PMPM ( $+108 \%$ relative to base case) for a commercial payer and to $\$ 0.016$ PMPM (+129\% relative to base case) for Medicare. Doubling the annual uptake of bevacizumab-bvzr was associated with average cost savings of \$0.023 PMPM (+92\% relative to base case) for a commercial payer and $\$ 0.013$ PMPM (+86\% relative to base case) for Medicare, while decreasing the bevacizumab-bvzr uptake by half was associated with average cost savings of \$0.006 PMPM $(-50 \%$ relative to base case) for a commercial payer and $\$ 0.003$ PMPM ( $-57 \%$ relative to base case) for Medicare. From a commercial payer perspective, increasing reimbursement markup relative to ASPs or WACs by $20 \%$ had limited effect on the budget impact, with average cost savings of $\$ 0.012$ PMPM (no change relative to base case). Decreasing the markups for ASPs or WACs by $20 \%$ was associated with slightly lower average cost savings of \$0.011 PMPM (- 8\% relative to base case) (Table 7).

\section{Discussion}

Our budget impact model has suggested that the introduction of bevacizumab-bvzr in the USA would lead to potential savings of $\$ 313,363$ for a 10 -million-member commercial payer and $\$ 92,880$ for 10-million-member Medicare in the first year, assuming that $1.7 \%$ of the patients currently treated with the reference product or bevacizumab-awwb would switch to bevacizumab-bvzr. Over a 5-year time horizon, approximately $\$ 7,030,924$ and $\$ 4,059,257$ could be saved in total for a commercial payer and Medicare, respectively. These cost savings could be more substantial from a full Medicare plan level, which covers 62 million Medicare beneficiaries in the US [47]. The introduction of bevacizumabbvzr could potentially lead to $\$ 25$ million savings over 5 years from a full Medicare plan level.

To our knowledge, the present study is the first budget impact analysis from a US payer perspective to incorporate all the latest Medicare Part B policies for biosimilar biologic products since 2016 . These policies include establishment of unique codes for each biosimilar, a granted pass-through status for biosimilar, assigning a specific payment rate to each biosimilar product rather than a single blended payment rate, and implementation of differential reimbursement to biosimilars [30]. Our findings should be interpreted with caution, as the estimated cost savings depend on a variety of interrelated factors such as biosimilar price discount relative to the reference product, biosimilar uptake rate, and patient access to biosimilar.

The significant savings on drug spending when patients switch from reference product and bevacizumab-awwb to bevacizumab-bvzr observed in the present study are consistent with previous biosimilar literature. A budget impact 


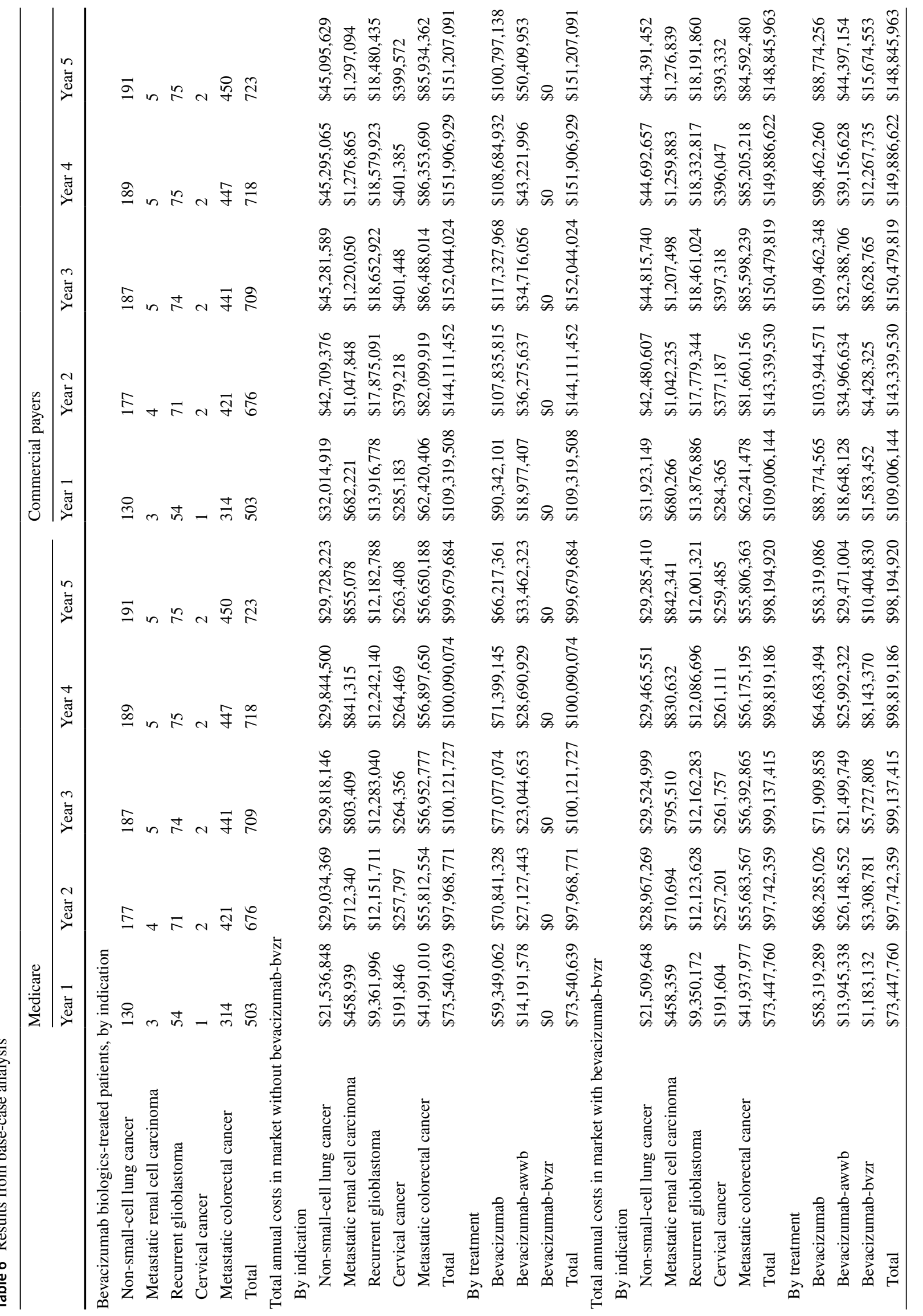


Budget Impact Analysis of Biosimilar Bevacizumab

613

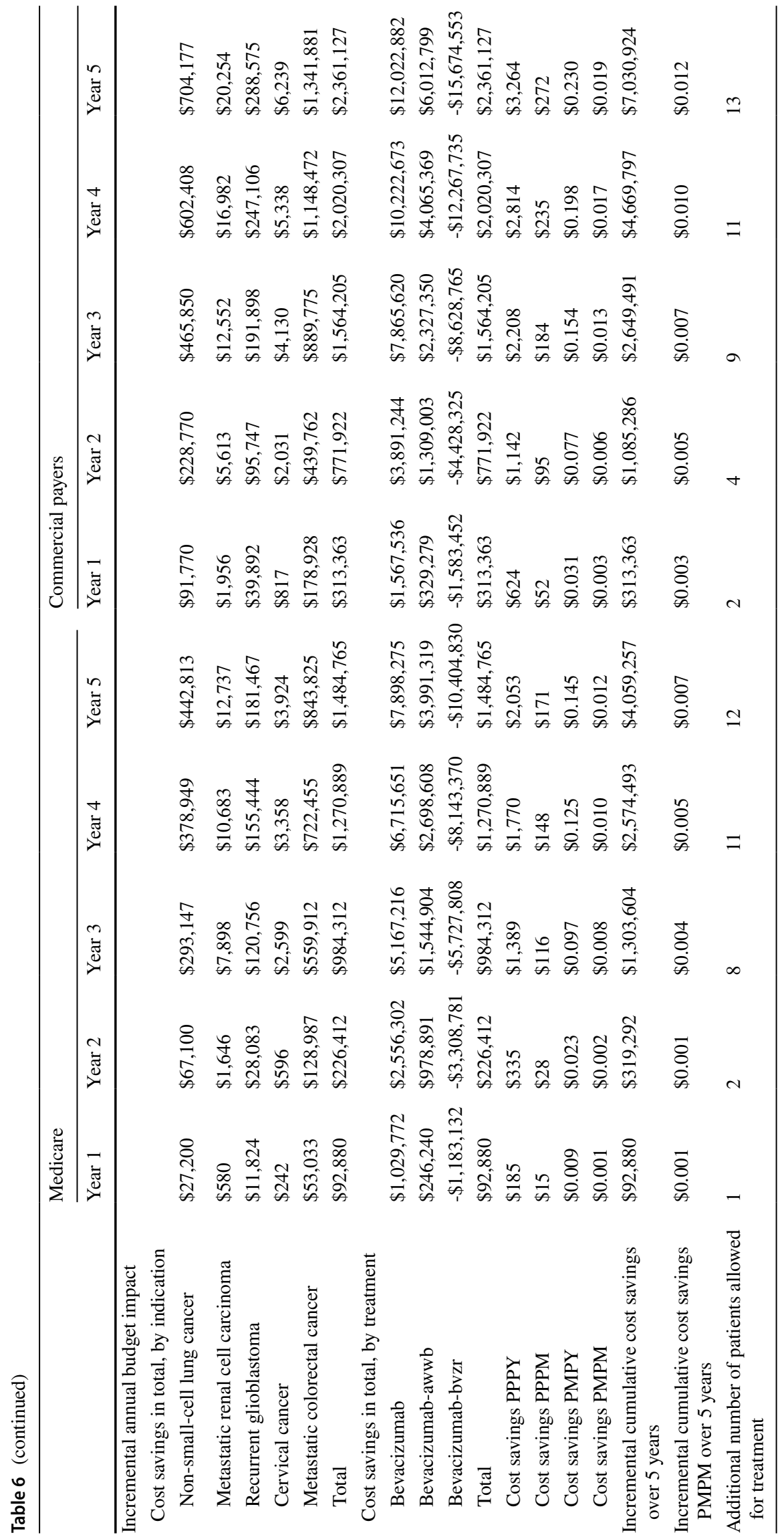

$\Delta$ Adis 
Table 7 Scenario analyses

\begin{tabular}{|c|c|c|c|c|c|c|}
\hline \multirow[t]{2}{*}{ Parameter } & \multirow[t]{2}{*}{ Base-case settings } & \multirow[t]{2}{*}{$\begin{array}{l}\text { Scenario-analysis set- } \\
\text { tings }\end{array}$} & \multicolumn{2}{|c|}{$\begin{array}{l}\text { Cost savings per member per month } \\
\text { averaged across a } 5 \text {-year time hori- } \\
\text { zon ( } \% \text { of changes from base case) }\end{array}$} & \multicolumn{2}{|c|}{$\begin{array}{l}\text { Additional patients treatable } \\
\text { with bevacizumab-bvzr aver- } \\
\text { aged across a 5-year time } \\
\text { horizon ( } \% \text { of changes from } \\
\text { base case) }\end{array}$} \\
\hline & & & Medicare & Commercial & Medicare & Commercial \\
\hline Base-case analysis & - & - & $\$ 0.007$ & $\$ 0.012$ & 7 & 8 \\
\hline $\begin{array}{l}\text { Market scenarios for } \\
\text { comparison }\end{array}$ & $\begin{array}{l}\text { Market with beva- } \\
\text { cizumab-bvzr vs. } \\
\text { market without } \\
\text { bevacizumab-bvzr }\end{array}$ & $\begin{array}{l}\text { Market with bevaci- } \\
\text { zumab biosimilars vs. } \\
\text { market without beva- } \\
\text { cizumab biosimilar }^{\text {a }}\end{array}$ & $\$ 0.05(+614 \%)$ & $\$ 0.093(+675 \%)$ & $50(+614 \%)$ & $62(+675 \%)$ \\
\hline \multirow{2}{*}{$\begin{array}{l}\text { Average sales price of } \\
\text { bevacizumab-bvzr }\end{array}$} & \multirow[t]{2}{*}{$\$ 631.8$} & $10 \%$ decrease $(\$ 568.6)$ & $\$ 0.011(+57 \%)$ & $\$ 0.018(+50 \%)$ & $13(+86 \%)$ & $14(+75 \%)$ \\
\hline & & $20 \%$ decrease $(\$ 505.4)$ & $\$ 0.016(+129 \%)$ & $\$ 0.025(+108 \%)$ & $20(+186 \%)$ & $21(+163 \%)$ \\
\hline \multirow[t]{2}{*}{$\begin{array}{l}\text { Uptake of bevaci- } \\
\text { zumab-bvzr over } \\
\text { years } 1-5\end{array}$} & \multirow[t]{2}{*}{$\begin{array}{r}1.7 \%, 3.6 \%, 6.7 \%, \\
9.4 \% \text {, and } 11.9 \%\end{array}$} & $\begin{array}{l}100 \% \text { increase }(3.5 \%, \\
7.2 \%, 13.4 \%, 18.8 \% \\
\text { and } 23.9 \%)^{\mathrm{b}}\end{array}$ & $\$ 0.013(+86 \%)$ & $\$ 0.023(+92 \%)$ & $13(+86 \%)$ & $15(+88 \%)$ \\
\hline & & $\begin{array}{l}50 \% \text { decrease }(0.9 \% \text {, } \\
1.8 \%, 3.4 \%, 4.7 \% \text { and } \\
6.0 \%)^{\mathrm{b}}\end{array}$ & $\$ 0.003(-57 \%)$ & $\$ 0.006(-50 \%)$ & $3(-57 \%)$ & $4(-50 \%)$ \\
\hline \multirow[t]{4}{*}{$\begin{array}{l}\text { Reimbursement markup } \\
\text { for a commercial } \\
\text { payer }\end{array}$} & \multirow[t]{2}{*}{$10 \%$ relative to ASPs } & $\begin{array}{l}20 \% \text { increase in ASP } \\
\text { markup (i.e., } 12 \% \\
\text { markup) }\end{array}$ & Not applicable & $\$ 0.012(0 \%)$ & Not applicable & $8(0 \%)$ \\
\hline & & $\begin{array}{l}20 \% \text { decrease in ASP } \\
\text { markup (i.e., } 8 \% \\
\text { markup) }\end{array}$ & Not applicable & $\$ 0.011(-8 \%)$ & Not applicable & $8(0 \%)$ \\
\hline & \multirow[t]{2}{*}{$75 \%$ relative to WACs } & $\begin{array}{l}20 \% \text { increase in WAC } \\
\text { markup (i.e., } 90 \% \\
\text { markup) }\end{array}$ & Not applicable & $\$ 0.012(0 \%)$ & Not applicable & $8(0 \%)$ \\
\hline & & $\begin{array}{l}20 \% \text { decrease in WAC } \\
\text { markup (i.e., } 60 \% \\
\text { markup) }\end{array}$ & Not applicable & $\$ 0.011(-8 \%)$ & Not applicable & $8(0 \%)$ \\
\hline \multirow[t]{2}{*}{ Time horizon } & \multirow[t]{2}{*}{5 years } & 1 year & $\$ 0.001(-86 \%)$ & $\$ 0.003(-75 \%)$ & $1(-86 \%)$ & $2(-75 \%)$ \\
\hline & & 3 years & $\$ 0.004(-43 \%)$ & $\$ 0.007(-42 \%)$ & $4(-43 \%)$ & $5(-38 \%)$ \\
\hline
\end{tabular}

${ }^{a}$ Market share in the market with bevacizumab biosimilars was the same as that in the market with bevacizumab-bvzr in the base case. In the market without bevacizumab biosimilar, bevacizumab reference product accounted for $100 \%$ of the market share

${ }^{\mathrm{b}}$ It was assumed that the market shift to bevacizumab-bvzr was proportionally taken from the bevacizumab reference product and bevacizumabawwb relative to the market share of bevacizumab reference product and bevacizumab-awwb

analysis of switching to biosimilar Trastuzumab (CT-P6) for the treatment of breast cancer and gastric cancer in 28 European countries projected budget savings from a payer's perspective between $€ 0.91$ billion and $€ 2.27$ billion over a 5-year time horizon, which would allow an additional 3503-7078 patients to be treated with trastuzumab [48]. A study performed in Croatia that estimated the budgetary impact of introducing biosimilar trastuzumab for the treatment of breast cancer also indicated savings ranging from $€ 0.26$ million to $€ 0.69$ million in the first year after introduction [49]. Another analysis carried out in the EU that evaluated the budgetary impact of the introduction of rituximab biosimilar (CT-P10) in patients with rheumatology and cancer showed projected savings of $€ 90.04$ million in the first year, which could convert to treatment opportunities for $6.4 \%$ more patients [50]. Grewal et al. conducted a US case analysis of cost savings for a filgrastim biosimilar. They estimated 5-year cost savings of \$256 million, of which 18\% were from reduced patient out-of-pocket costs, $34 \%$ were savings for commercial payers, and $48 \%$ were savings for Medicare [51].

The net budget impact was sensitive to market uptake rates and the price discount applied to biosimilars. In the filgrastim-sndz (Zarxio) case, which was the first biosimilar launched in the USA, a 30\% decrease in overall drug spending on any filgrastim products was seen in the Medicare Part B program following a sharply increased utilization and gradually decreased ASP of the biosimilar, filgrastim-sndz [52]. It was reported that by March 2018, approximately 3 years after its launch, filgrastim-sndz accounted for $47 \%$ of filgrastim use among commercially insured and $42 \%$ among Medicare Advantage beneficiaries [53]. The price difference 
between filgrastim-sndz and its originator was more than $30 \%$ [53].

However, several features of the current US healthcare system may hamper biosimilar uptake. First of all, policies on biosimilar reimbursement and insurer coverage can have a strong influence on the potential savings that biosimilars can bring. For biosimilars that are covered under medical benefit and reimbursed using the "buy-and-bill" method, the current reimbursement model set up by commercial payers may disincentivize providers from adopting lower-cost biosimilars. In order to avoid disincentivizing biosimilars in Medicare, CMS reimburses providers at the biosimilar's ASP plus a markup of $6 \%$ of the reference ASP, which equalizes the cost recovery of biosimilars to reference products [30]. However, in 2019, among 17 of the largest US commercial health plans, only $14 \%$ granted biosimilars preferred coverage, $33 \%$ nonpreferred coverage, and $53 \%$ on-par coverage [54]. A lack of preferred coverage among commercial health plans may also explain the slow uptake. Second, oncologists and pharmacists in the USA have inventory management, regulatory, and administrative considerations for biosimilar substitutions [55], such as pharmacovigilance requirements, education, tracking, and product characteristics (e.g., labeling, package, storage and supply chain) [55]. Most states, for example, require that pharmacists notify prescribers and patients of interchangeable biosimilar substitutions [56]. However, notification requirements may compromise the role of pharmacists in driving biosimilar adoption. A survey of 781 members of the Academy of Managed Care Pharmacy and the Hematology/Oncology Pharmacy Association has shown that the biosimilar post-dispense notification requirements may impact willingness of some pharmacists to substitute [57]. FDA guidance on pharmacy-level substitution of reference biologics with biosimilars may help to overcome biosimilar adoption challenges in the USA [58]. In terms of treating physicians, key considerations include (1) how adverse events should be tracked or reported; (2) how they should document if switching occurs over the planned course of treatment; and (3) how to evaluate the financial burden of patients with different health plans that may have different patient cost sharing strategies for biosimilar versus reference products [59]. Hence, there is a crucial need for treating physicians to have a better understanding of biosimilars in order to make informed decisions. Lastly, biosimilars are also facing legal actions, patents, and exclusivity, for which many solutions have been proposed [60].

Also, substantial skepticism among physicians and other key stakeholders relating to the efficacy and safety of biosimilars remains. A survey of a national sample of New Zealand medical specialists has indicated that physicians held generally positive attitudes towards biosimilars, but were less confident in biosimilar indication extrapolation or switching [61]. In a survey of 300 managed-care and specialty pharmacy professionals, the strategy rated most likely to overcome barriers to biosimilar adaptation was prescriber education about evidence from switching studies [58]. Aside from prescribers, patient education will likely accelerate biosimilar's integration into clinical practice. In an international survey of 3,198 patients, only $6 \%$ of the participants had a basic awareness of biosimilars while the majority did not know what biosimilar medicines were [62]. Patients who were aware of biosimilars were more willing to switch [62]. Hence, patients must be educated to understand the definition of biosimilars and the regulatory process that leads to approval of biosimilar. Particularly, it should be emphasized that clinical equivalence is established through a series of preclinical and clinical trial data. Most importantly, stakeholders should be aware of the potential savings and increased access that biosimilars can bring to biological therapies.

\subsection{Limitations}

Our study had several limitations. First, the major cost driver between biosimilar and reference product was the difference in ASP or other drug pricing benchmarks alone [63]. However, we did not take into account costs associated with education, formulary management, and additional laboratory tests/procedures. Second, the reimbursement of medical products for commercial payers, a percentage of billed charges was assumed in the present analysis. However, it is worth noting that each commercial payer has their own formulary decisions/coverage for biosimilars. Our results may under- or overestimate the cost savings on an individual plan level. Third, the use of bevacizumab treatment is likely changing given the introduction of innovative targeted therapies and immune-oncology drugs. Fluctuations in the use of bevacizumab treatment will affect our projected savings. Fourth, the epidemiology inputs used to estimate target population were assumed to be the same for commercial payers and Medicare. However, it is acknowledged that the distribution of demographics could vary between a commercially insured population and a Medicare population. Future studies with claims data from specific payers are needed to improve the accuracy of the estimated cost savings. Fifth, given the trial data did not report range of treatment duration, additional scenario analysis may be required with varying treatment durations to assess its impact on the results. Finally, as more bevacizumab biosimilar products enter the US market, the competition may accelerate price decreases for both reference product and biosimilars, which may result in even greater savings. However, the timing of entry and magnitude of price decrease is uncertain. 


\section{Conclusion}

Our budget impact analysis suggested a substantial cost savings from the introduction of the biosimilar bevacizumabbvzr, primarily driven by the lower cost of bevacizumab-bvzr relative to its reference product, from a US payer perspective. The exact cost-saving estimates may vary depending on a variety of factors such as rebates, biosimilar uptake and price discount relative to the reference product.

Previous Presentations Budget Impact Analysis of Introduction of Bevacizumab Biosimilar in the USA from a Payer Perspective. ISPOR. Virtual ISPOR 2020, 18-20 May 2020. Poster Presentation.

Acknowledgements Editorial assistance was provided by Greg Poorman, Pharmerit, an OPEN Health Company, Bethesda, MD, USA. Greg Poorman is an employee of Pharmerit, an OPEN Health Company.

Author Contributions JY: Conceptualization, methodology, wrote the original draft. RL: Conceptualization, methodology, modeling, manuscript review, and revisions. VE: Conceptualization, methodology, supervision, manuscript review, and revision. JS: Conceptualization, supervision, manuscript review, and revisions. AS: Conceptualization, supervision, manuscript review, and revisions. All authors approved of the final version of the manuscript to be published and agree to be accountable for all aspects of the work.

Funding Research funding was provided by Pfizer Inc. Medical writing support was provided by Greg Poorman at Pharmerit, an OPEN Health Company, and was funded by Pfizer.

Availability of data and material Available upon request.

\section{Declarations}

Declaration of financial/other relationships Varun Ektare, Rongzhe Liu, and Jennifer Stephens are employees of Pharmerit-an OPEN Health Company, which received research funding from Pfizer Inc. Jingyan Yang and Ahmed Shelbaya are employees of Pfizer Inc. and own Pfizer stock.

Open Access This article is licensed under a Creative Commons Attribution-NonCommercial 4.0 International License, which permits any non-commercial use, sharing, adaptation, distribution and reproduction in any medium or format, as long as you give appropriate credit to the original author(s) and the source, provide a link to the Creative Commons licence, and indicate if changes were made. The images or other third party material in this article are included in the article's Creative Commons licence, unless indicated otherwise in a credit line to the material. If material is not included in the article's Creative Commons licence and your intended use is not permitted by statutory regulation or exceeds the permitted use, you will need to obtain permission directly from the copyright holder. To view a copy of this licence, visit http://creativecommons.org/licenses/by-nc/4.0/.

\section{References}

1. Al-Husein B, Abdalla M, Trepte M, Deremer DL, Somanath PR. Antiangiogenic therapy for cancer: an update. Pharmacotherapy. 2012;32(12):1095-111.

2. Cohen MH, Gootenberg J Fau - Keegan P, Keegan P Fau - Pazdur R, Pazdur R. FDA drug approval summary: bevacizumab plus FOLFOX4 as second-line treatment of colorectal cancer. Oncologist. 2007(1083-7159 (Print)).

3. Sandler A, Gray R, Perry MC, et al. Paclitaxel-carboplatin alone or with bevacizumab for non-small-cell lung cancer. N Engl J Med. 2006;355(24):2542-50.

4. Escudier B, Pluzanska A, Koralewski P, et al. Bevacizumab plus interferon alfa- 2 a for treatment of metastatic renal cell carcinoma: a randomised, double-blind phase III trial. Lancet. 2007;370(9605):2103-11.

5. Wick W, Gorlia T, Bendszus M, et al. Lomustine and bevacizumab in progressive glioblastoma. N Engl J Med. 2017;377(20):1954-63.

6. Penson RT, Huang HQ, Wenzel LB, et al. Bevacizumab for advanced cervical cancer: patient-reported outcomes of a randomised, phase 3 trial (NRG Oncology-Gynecologic Oncology Group protocol 240). Lancet Oncol. 2015;16(3):301-11.

7. Finn RS, Qin S, Ikeda M, et al. Atezolizumab plus Bevacizumab in Unresectable Hepatocellular Carcinoma. N Engl J Med. 2020(1533-4406).

8. Hurwitz H, Fehrenbacher L, Novotny W, et al. Bevacizumab plus irinotecan, fluorouracil, and leucovorin for metastatic colorectal cancer. N Engl J Med. 2004;350(23):2335-42.

9. Giantonio BJ, Catalano PJ, Meropol NJ, et al. Bevacizumab in combination with oxaliplatin, fluorouracil, and leucovorin (FOLFOX4) for previously treated metastatic colorectal cancer: results from the Eastern Cooperative Oncology Group Study E3200. J Clin Oncol. 2007;25(12):1539-44.

10. Burger RA, Brady MF, Bookman MA, et al. Incorporation of bevacizumab in the primary treatment of ovarian cancer. N Engl J Med. 2011;365(26):2473-83.

11. Ferrara N, Adamis AP. Ten years of anti-vascular endothelial growth factor therapy. Nat Rev Drug Discov. 2016(1474-1784).

12. Al-Abd AM, Alamoudi AJ, Abdel-Naim AB, Neamatallah TA Ashour OM. Anti-angiogenic agents for the treatment of solid tumors: Potential pathways, therapy and current strategies-a review. J Adv Res. 2017(2090-1232 (Print)).

13. Garcia J, Hurwitz HI, Sandler AB, et al. Bevacizumab (Avastin ${ }^{\circledR}$ ) in cancer treatment: a review of 15 years of clinical experience and future outlook. Cancer Treat Rev. 2020;86:102017.

14. Gottlieb S. Remarks from FDA Commissioner Scott Gottlieb, M.D., as prepared for delivery at the Brookings Institution on the release of the FDA's Biosimilars Action Plan. In:2018.

15. Monk BJ, Lammers PE, Cartwright T, Jacobs I. Barriers to the Access of Bevacizumab in Patients with Solid Tumors and the Potential Impact of Biosimilars: A Physician Survey. Pharmaceuticals (Basel). 2017;10(1).

16. Goldstein DA, Chen Q, Ayer T, et al. Bevacizumab for metastatic colorectal cancer: a global cost-effectiveness analysis. Oncologist. 2017;22(6):694-9.

17. Goldstein DA, Chen Q, Ayer T, et al. First- and second-line bevacizumab in addition to chemotherapy for metastatic colorectal cancer: a united states-based cost-effectiveness analysis. J Clin Oncol. 2015;33(10):1112-8.

18. Carter HE, Zannino D, John Simes R, et al. The cost effectiveness of bevacizumab when added to capecitabine, with or without 
mitomycin-C, in first line treatment of metastatic colorectal cancer: results from the Australasian phase III MAX study. Eur J Cancer. 2014;50(3):535-43.

19. Kovic B, Xie F. Economic evaluation of bevacizumab for the firstline treatment of newly diagnosed glioblastoma multiforme. J Clin Oncol. 2015;33(20):2296-302.

20. Shao C, Siddiqui MK, Takyar J, Zhou W, Sen S. Economic burden of advanced cervical cancer: a systematic literature review. Value Health. 2018;21:S27.

21. Ball G, Xie F, Tarride JE. Economic evaluation of bevacizumab for treatment of platinum-resistant recurrent ovarian cancer in Canada. Pharmacoecon Open. 2018;2(1):19-29.

22. Neyt M, Vlayen J, Devriese S, Camberlin C. First- and second-line bevacizumab in ovarian cancer: a Belgian cost-utility analysis. PLoS One. 2018;13(4):e0195134.

23. Lange A, Prenzler A, Frank M, Golpon H, Welte T, von der Schulenburg JM. A systematic review of the cost-effectiveness of targeted therapies for metastatic non-small cell lung cancer (NSCLC). BMC Pulm Med. 2014;14:192.

24. Centers for Medicare \& Medicaid Services. Medicare Part B Drug Spending Dashboard. https://www.cms.gov/Research-Statistics -Data-and-Systems/Statistics-Trends-and-Reports/Information-onPrescription-Drugs/MedicarePartB. Published 2019. Accessed 9 Dec 2019.

25. Mulcahy Aw Fau - Hlavka JP, Hlavka Jp Fau - Case SR, Case SR. Biosimilar Cost Savings in the United States: Initial Experience and Future Potential. Rand Health Q. 2018(2162-8254 (Print)).

26. Gottlieb S. Biosimilars: policy, clinical, and regulatory considerations. Am J Health Syst Pharm. (1535-2900).

27. Food and Drug Administration. Search Orphan Drug Designations and Approvals: Bevacizumab for therapeutic treatment of patients with ovarian cancer. https://www.accessdata.fda.gov/ scripts/opdlisting/oopd/detailedIndex.cfm?cfgridkey $=216405$. Accessed November 8, 2018.

28. Li E, Hoffman JM. Implications of the FDA draft guidance on biosimilars for clinicians: what we know and don't know. J Natl Compr Canc Netw. 2013(1540-1413).

29. Reinmuth NA-O, Bryl M, Bondarenko I, et al. PF-06439535 (a Bevacizumab Biosimilar) Compared with Reference Bevacizumab (Avastin(®)), Both Plus Paclitaxel and Carboplatin, as FirstLine Treatment for Advanced Non-Squamous Non-Small-Cell Lung Cancer: A Randomized, Double-Blind Study. BioDrugs. 2019(1179-190X)

30. Centers for Medicare \& Medicaid Services. Centers for Medicare \& Medicaid Services, HHS, 42 C.F.R. $§ 405,410,411,414,425$, 495. https://www.gpo.gov/fdsys/pkg/FR-2015-11-16/pdf/201528005.pdf. Published 2015. Accessed.

31. Sullivan SD, Mauskopf JA, Augustovski F, et al. Budget impact analysis-principles of good practice: report of the ISPOR 2012 Budget Impact Analysis Good Practice II Task Force. Value Health. 2014;17(1):5-14.

32. Husereau D, Drummond M, Petrou S, et al. Consolidated health economic evaluation reporting standards (CHEERS) statement. PharmacoEconomics. 2013;31(5):361-7.

33. Noone A, Howlader N, Krapcho M, et al. SEER cancer statistics review, 1975-2015, National Cancer Institute. Bethesda, MD, https://seer.cancer.gov/csr/1975_2015/, based on November 2017 SEER data submission, posted to the SEER web site. 2018.

34. IQVIA Drug Distribution Data (DDD), IQVIA Inc., Durham, NC. 2020.

35. Fein AJ. How Outrageous Hospital Markups Hike Drug Spending. Drug Channels Web site. https://www.drugchannels.net/2016/04/ new-data-how-outrageous-hospital.html. Published 2016. Accessed 25 July 2020.

36. Reddan J, Moore J, Snyder E, Yang Z. Biosimilars: When LowerCost Medications Mean Lower Provider Profits. Guidehouse. https ://guidehouse.com/insights/life-sciences-consulting/2017/biosimilar s-lower-cost-medications. Published 2017. Accessed 25 July 2020.

37. Carioto J, Mirchandani H. Barriers and potential paths for biosimilars in the United States. Milliman, Inc. https://us.milliman. com/en/insight/barriers-and-potential-paths-for-biosimilars-inthe-united-states. Published 2018. Accessed 25 July 2020.

38. Sorensen S, Ellis L, Wu Y, Hutchins V, Linnehan JE, Senbetta M. Budgetary impact on a U.S. health plan adopting abiraterone acetate plus prednisone for the treatment of patients with metastatic castration-resistant prostate cancer. J Manag Care Pharm. 2013;19(9):799-808.

39. Allegra CJ, Yothers G, O'Connell MJ, et al. Bevacizumab in stage II-III colon cancer: 5-year update of the National Surgical Adjuvant Breast and Bowel Project C-08 trial. J Clin Oncol. 2013;31(3):359-64.

40. Abramowitz L, Lacau Saint Guily J, Moyal-Barracco $M$, et al. Epidemiological and economic burden of potentially HPV-related cancers in France. PloS One. 2018;13(9):e0202564-e0202564.

41. Forys A. 340B Changes: What Biosimilar Manufacturers Need to Know. AJMC Center for Biosimilars. https://www.centerforb iosimilars.com/contributor/amanda-forys/2018/02/340b-chang es-what-biosimilar-manufacturers-need-to-know. Published 2018. Accessed 22 July 2020.

42. July 2020 ASP Pricing File. Centers for Medicare \& Medicaid Services. https://www.cms.gov/medicare/medicare-part-b-drugaverage-sales-price/2020-asp-drug-pricing-files. Published 2020. Accessed.

43. RED BOOK Online. IBM Micromedix. micromedixsolutions. com. Published 2020. Accessed 25 July 2020.

44. International Agency for Research on Cancer (IARC) and World Health Organization (WHO). Global Cancer Observatory. http:// gco.iarc.fr/. Published 2019. Accessed 15 Aug 2019.

45. Centers for Disease Control and Prevention. National Center for Health Statistics. Body measurement [Updated 2017]. https:// www.cdc.gov/nchs/fastats/body-measurements.htm. Published 2017. Accessed 22 Oct 2018.

46. ZIRABEV [prescribing information], New York, NY: Pfizer Inc. 2019. https://www.accessdata.fda.gov/drugsatfda_docs/label /2019/761099s000lbl.pdf.

47. Centers for Medicare \& Medicaid Services. Medicare Enrollment Dashboard. https://www.cms.gov/Research-Statistics-Data-andSystems/Statistics-Trends-and-Reports/Dashboard/MedicareEnrollment/Enrollment\%20Dashboard.html. Published 2020. Accessed 27 Oct 2020.

48. Lee SM, Jung JH, Suh D, et al. Budget Impact of Switching to Biosimilar Trastuzumab (CT-P6) for the Treatment of Breast Cancer and Gastric Cancer in 28 European Countries. BioDrugs. 2019(1179-190X).

49. Cesarec A, Likić RA-O. Budget Impact Analysis of Biosimilar Trastuzumab for the Treatment of Breast Cancer in Croatia. Appl Health Econ Health Policy. (1179-1896).

50. Gulácsi L, Brodszky V, Baji P, Rencz F, Péntek M. The Rituximab Biosimilar CT-P10 in Rheumatology and Cancer: A Budget Impact Analysis in 28 European Countries. Adv Ther. 2017(1865-8652).

51. Grewal S, Ramsey S, Balu S, Carlson JJ. Cost-savings for biosimilars in the United States: a theoretical framework and budget impact case study application using filgrastim. Expert Rev Pharmacoecon Outcomes Res. 2018(1744-8379).

52. Socal MP, Anderson KE, Sen A, Bai G, Anderson GF. Biosimilar Uptake in Medicare Part B Varied Across Hospital Outpatient Departments and Physician Practices: The Case of Filgrastim. Value Health. 2020(1524-4733).

53. Karaca-Mandic P, Chang J, Go R, Schondelmeyer S, Weisdorf D, Jeffery MM. Biosimilar Filgrastim Uptake And Costs 
Among Commercially Insured, Medicare Advantage. Health Aff. 2019(1544-5208).

54. Chambers JD, Lai RC, Margaretos NM, Panzer AD, Cohen JT, Neumann PJ. Coverage for Biosimilars vs Reference Products Among US Commercial Health Plans. JAMA. 2020(1538-3598).

55. Ventola CL. Evaluation of Biosimilars for Formulary Inclusion: Factors for Consideration by P\&T Committees. P T. 2015(10521372 (Print)).

56. Stevenson JG, Popovian R, Jacobs I, Hurst S, Shane LG. Biosimilars: Practical Considerations for Pharmacists. Ann Pharmacother. 2017(1542-6270).

57. Tomaszewski D. Biosimilar Naming Conventions: Pharmacist Perceptions and Impact on Confidence in Dispensing Biologics. J Manag Care Spec Pharm. 2016(2376-1032).

58. Greene L, Singh RM, Carden MJ, Pardo CO, Lichtenstein GR. Strategies for Overcoming Barriers to Adopting Biosimilars and Achieving Goals of the Biologics Price Competition and Innovation Act: A Survey of Managed Care and Specialty Pharmacy Professionals. J Manag Care Spec Pharm. 2019(2376-1032).

59. Camacho LH, Frost Cp Fau - Abella E, Abella E Fau - Morrow PK, Morrow Pk Fau - Whittaker S, Whittaker S. Biosimilars 101: considerations for U.S. oncologists in clinical practice. Cancer Med. (2045-7634).

60. Zhai Mz Fau - Sarpatwari A, Sarpatwari A, Kesselheim AS. Why Are Biosimilars Not Living up to Their Promise in the US? Ama J Ethics. 2019(2376-6980).

61. Hemmington A, Dalbeth N, Jarrett P, et al. Medical specialists' attitudes to prescribing biosimilars. Pharmacoepidemiol Drug Saf. 2017(1099-1557).

62. Jacobs I, Singh E, Sewell KL, Al-Sabbagh A, Shane LG. Patient attitudes and understanding about biosimilars: an international cross-sectional survey. Patient Prefer Adherence. 2016(1177889X (Print))

63. Santye L. Biosimilar Uptake Challenges: Low-Cost Specialty Drugs Reduce Provider Profits. https://www.pharmacytimes. com/news/biosimilar-uptake-challenges-low-cost-specialty-drugs -reduce-provider-profits. Published 2017. Accessed 12 Aug 2019.

64. Centers for Disease Control and Prevention. National population projections 2014-2060 results. https://wonder.cdc.gov/controller /datarequest/D117. Accessed 11 Nov 2018.

65. Base NCD. http://oliver.facs.org/BMPub. Published 2015. Updated 2015. Accessed 10 Oct 2018.

66. Chen VW, Ruiz BA, Hsieh MC, Wu XC, Ries LA, Lewis DR. Analysis of stage and clinical/prognostic factors for lung cancer from SEER registries: AJCC staging and collaborative stage data collection system. Cancer. 2014;120:3781-92.

67. Orsini L, Korytowsky B, Petrilla A, et al. Real-world use of systemic anticancer treatment by histology and line of therapy in US Medicare patients with advanced non-small cell lung cancer: outcomes/health services research. Int J Radiat Oncol Bio Phys. 2014;90(5):S58-9.

68. Bittoni MA, Arunachalam A, Li H, et al. Real-world treatment patterns, overall survival, and occurrence and costs of adverse events associated with first-line therapies for medicare patients 65 years and older with advanced non-small-cell lung cancer: a retrospective study. Clin Lung Cancer. 2018;19(5):e629-45.

69. Copher R, Lin J, Chatterjee D, et al. Treatment patterns and effectiveness outcomes in patients with stage IV, renal cell carcinoma. J Clin Oncol. 2018;36(15_suppl):e16571-e16571.

70. Stukalin I, Wells JC, Fraccon A, et al. Fourth-Line Therapy in Metastatic Renal Cell Carcinoma (mRCC): Results from the International mRCC Database Consortium (IMDC). Kidney Cancer. 2018(Preprint):1-6.

71. Aly A, Singh P, Korytowsky B, et al. Overall survival (OS) by line of therapy (LOT) in Medicare-enrolled glioblastoma multiforme (GBM) patients (pts). J Clin Oncol. 2017;35(15_suppl):2039-2039.

72. Byrne K, Waller J, Piercy J, Shaw J, Dastani H. P02.03 Real-world treatment patterns in glioblastoma multiforme (GBM). Neuro Oncol. 2017;19(Suppl 3):iii32-iii32.

73. Guskova E, Kit OI, Nerodo GA, et al. Prognostic factors of cervical cancer recurrence. J Clin Oncol. 2016;34(15_suppl):e17025-e17025.

74. Shao C, He J, Nwankwo C, Stein K, Keefe SM. Real-world treatment patterns, survival, and cost among elderly cervical cancer patients. J Clin Oncol. 2019;37(15_suppl):e18226-e18226.

75. Ansa BE, Coughlin SS, Alema-Mensah E, Smith SA. Evaluation of Colorectal Cancer Incidence Trends in the United States (2000-2014). J Clin Med. 2018;7(2).

76. Zhong Y, Kamalakar R, Asche CV, Anderson S, Seal BS. Treatment patterns of patients with metastatic colorectal cancer in a large national U.S. claims-based data. J Clin Oncol. 2014;32(30_suppl):268-268.

77. Hess LM, Cui ZL, Mytelka DS, Han Y, Goodloe R, Schelman W. Treatment patterns and survival outcomes for patients receiving second-line treatment for metastatic colorectal cancer in the USA. Int J Colorectal Dis. 2019;34(4):581-8.

78. Wagstaff J, Jones R, Hawkins R, et al. Treatment patterns and clinical outcomes in patients with renal cell carcinoma in the UK: insights from the RECCORD registry. Ann Oncol. 2015;27(1):159-65.

79. Dibonaventura M, Higginbottom K, Meyers A, Morimoto Y, Ilacqua J. Treatment pattern differences across the United States, Western Europe, and Japan among patients with metastatic renal cell carcinoma. Value Health. 2016;19(7):A764.

80. Sandler A, Yi J, Dahlberg S, et al. Treatment outcomes by tumor histology in Eastern Cooperative Group Study E4599 of bevacizumab with paclitaxel/carboplatin for advanced non-small cell lung cancer. J Thorac Oncol. 2010;5(9):1416-23.

81. Tewari KS, Sill MW, Long HJ III, et al. Improved survival with bevacizumab in advanced cervical cancer. N Engl J Med. 2014;370(8):734-43.

82. Bennouna J, Sastre J, Arnold D, et al. Continuation of bevacizumab after first progression in metastatic colorectal cancer (ML18147): a randomised phase 3 trial. Lancet Oncol. 2013;14(1):29-37. 